\title{
PERFORMANCE OF V-4Cr-4Ti ALLOY EXPOSED TO THE JFT-2M TOKAMAK ENVIRONMENT
}

\author{
by \\ W.R. JOHNSON, P.W. TRESTER, S. SENGOKU, ${ }^{*}$ S. ISHIYAMA, ${ }^{*}$ \\ K. FUKAYA, ${ }^{*}$ M. ETO, ${ }^{\star}$ T. ODA, ${ }^{\dagger}$ Y. HIROHATA, ${ }^{\dagger}$ \\ T. HINO, ${ }^{\dagger}$ and H. TSAl
}

This is a preprint of a paper to be presented at the 9th International Conference on Fusion Reactor Materials, Colorado Springs, Colorado, to be printed in the Proceedings.

*Japan Atomic Energy Research Institute, Tokai, Naka, Ibaraki, Japan tDepartment of Nuclear Engineering, Hokkaido University, Sapporo, Japan ‡Argonne National Laboratory, Argonne, Illinois, USA

Work supported by

the U.S. Department of Energy

under Contract Nos. DE-AC03-99ER54463

W-31-109-ENG-38, and internal GA IR\&D funds

GA PROJECT 04437 and 30033 OCTOBER 1999 


\section{DISCLAIMER}

This report was prepared as an account of work sponsored by an agency of the United States Government. Neither the United States Government nor any agency thereof, nor any of their employees, make any warranty, express or implied, or assumes any legal liability or responsibility for the accuracy, completeness, or usefulness of any information, apparatus, product, or process disclosed, or represents that its use would not infringe privately owned rights. Reference herein to any specific commercial product, process, or service by trade name, trademark, manufacturer, or otherwise does not necessarily constitute or imply its endorsement, recommendation, or favoring by the United States Government or any agency thereof. The views and opinions of authors expressed herein do not necessarily state or reflect those of the United States Government or any agency thereof. 


\section{DISCLAIMER}

Portions of this document may be illegible in electronic image products. Images are produced from the best available original document. 


\begin{abstract}
A long-term test has been conducted in the JFT-2M tokamak fusion device to determine the effects of environmental exposure on the mechanical and chemical behavior of a $\mathrm{V}-4 \mathrm{Cr}-4 \mathrm{Ti}$ alloy. Test specimens of the alloy were exposed in the outward lower divertor chamber of JFT-2M in a region away from direct contact with the plasma and were preheated to $300^{\circ} \mathrm{C}$ just prior to and during selected plasma discharges. During their nine-month residence time in JFT-2M, the specimens experienced approximately 200 lower single-null divertor shots at $300^{\circ} \mathrm{C}$, during which high energy particle fluxes to the preheated test specimens were significant, and approximately 2,010 upper single-null divertor shots and non-divertor shots at room temperature, for which high energy particle fluxes to and expected particle retention in the test specimens were very low. Data from post-exposure tests have indicated that the performance of the $\mathrm{V}-4 \mathrm{Cr}-4 \mathrm{Ti}$ alloy would not be significantly affected by environmental exposure to gaseous species at partial pressures typical for tokamak operation. Deuterium retention in the exposed alloy was also low $(<2 \mathrm{ppm})$. Absorption of interstitials by the alloy was limited to the very near surface, and neither the strength nor the Charpy impact properties of the alloy appeared to be significantly changed from the exposure to the JFT-2M tokamak environment.
\end{abstract}




\section{INTRODUCTION}

One of the most promising features of fusion as a future energy source is its potential for low environmental impact [1,2]. In order to realize this potential, however, materials which have low neutron activation and rapid activation decay must be used in the construction of fusion systems. Vanadium-chromium-titanium alloys are attractive for fusion systems because they not only exhibit inherently low neutron-induced activation, but they also exhibit high resistance to swelling and good thermal and mechanical properties required for high temperature system performance $[3,4]$. A V-4Cr-4Ti alloy has been selected in the U.S. as the current leading candidate for structures behind the first wall region.

In 1995, General Atomics (GA), in conjunction with the Department of Energy's (DOE) DIII-D Program, developed a plan for the utilization of this vanadium alloy in the DIII-D tokamak $[2,5,6]$. This plan was to culminate in the installation and operation in DIII-D of fullsize components fabricated from a large heat of $\mathrm{V}-4 \mathrm{Cr}-4 \mathrm{Ti}$ alloy to be procured for the program [7-10].

To this end, a large heat $(1200 \mathrm{~kg})$ of $\mathrm{V}-4 \mathrm{Cr}-4 \mathrm{Ti}$ alloy was procured [Teledyne Wah Chang (now Oremet Wah Chang) of Albany, Oregon] [11], and studies were conducted to develop appropriate techniques applicable to the fabrication of the large-scale components [12]. In addition, because the components were expected to be exposed to a wide range of environmental conditions that could affect the properties of the material, coupon-size specimens were exposed in DIII-D to a range of temperatures and impurity conditions typical of today's tokamak plasma physics experiments in order to obtain early performance data. Data from the test series indicated that the performance of the alloy was not significantly affected by the environmental exposure [13-15].

As a continuation of this investigative effort to assess the effects of a tokamak environment on the behavior of the alloy, additional specimens of the V-4Cr-4Ti alloy were long-term exposed in the JFT-2M tokamak in Japan under the auspices of the Japan Atomic Energy Research Institute (JAERI). The results of tests on the post-exposed specimens are the subject of this paper. 


\section{OBJECTIVE}

In service, large-scale V-alloy components in fusion systems of the future will be exposed to a range of temperatures and impurity conditions typical of today's tokamak plasma physics experiments. These conditions include: alternating vacuum/low-pressure hydrogen and/or deuterium plasma operation; indirect particle flux; thermal cycles and periodic bakeout; various periodic internal surface cleaning and conditioning processes (e.g., He glow discharge cleaning, boron or titanium coating, etc.); and occasional re-exposure to air during vents for maintenance. The objective of the test specimen exposures in DIII-D and in JFT-2M is to determine the effects of these environmental exposures on the performance of the $\mathrm{V}-4 \mathrm{Cr}-4 \mathrm{Ti}$ alloy. Of particular importance is to determine whether interstitial impurities $(\mathrm{O}, \mathrm{H}, \mathrm{C}$, and $\mathrm{N})$ are absorbed in quantities sufficient to cause significant changes in mechanical properties and material embrittlement. In the previous DIII-D exposures, the test specimens were not heated during plasma exposure, and experienced elevated temperatures $\left(-300^{\circ} \mathrm{C}\right)$ only during periodic vessel bakeouts during nonplasma operations [13-15]. For the exposure in JFT-2M, however, the specimens were intentionally heated during plasma operation as particle interactions and retention in the alloy were expected to be greater. 


\section{EXPERIMENT AND SPECIMEN DESCRIPTION}

\subsection{TEST SPECIMENS}

The chemistry of the heat of V-4Cr-4Ti alloy used in this study (Heat No. 832864) and annealed sheet microstructure have been previously reported [11]. Test specimens fabricated by GA and provided to JAERI for exposure in JFT-2M included standard bend $(10 \mathrm{~mm} \times 4.5 \mathrm{~mm} \times$ $55 \mathrm{~mm}$ long); full-size Charpy V-Notch (CVN) impact (10 $\mathrm{mm} \times 4.5 \mathrm{~mm} \times 55 \mathrm{~mm}$ long with a $45^{\circ}, 2 \mathrm{~mm}$ deep, $0.25 \mathrm{~mm}$ root radius notch); miniature (one-third size) CVN impact ( $3.3 \mathrm{~mm} \times$ $3.3 \mathrm{~mm} \times 25.4 \mathrm{~mm}$ long with a $30^{\circ}, 0.6 \mathrm{~mm}$ deep, $0.08 \mathrm{~mm}$ root radius notch); tensile $(12 \mathrm{~mm} \times$ $1 \mathrm{~mm}$ thick $\times 55 \mathrm{~mm}$ long with a $23 \mathrm{~mm} \times 4 \mathrm{~mm}$ gauge section); hardness and chemical analysis test specimens $(10 \mathrm{~mm} \times 10 \mathrm{~mm} \times 2 \mathrm{~mm}$ thick$)$.

All specimens were machined from as-warm-rolled $\left(400^{\circ} \mathrm{C}\right) 4.8 \mathrm{~mm}$ thick $\mathrm{V}-4 \mathrm{Cr}-4 \mathrm{Ti}$ alloy sheet [8-11], with the short transverse dimension of each specimen taken through the thickness of the sheet. The longitudinal direction of each specimen was taken parallel with the rolling direction. The direction of the crack plane for the standard CVN specimens was perpendicular to the rolling direction and parallel to the width of the sheet, and for the miniature CVN specimens was perpendicular to the rolling direction and through the sheet thickness. The faces of all specimens were machined to a $1.6 \mu \mathrm{m}$ finish. In addition, the chemistry and hardness samples were hand ground on $5 \mu \mathrm{m}$ silicon carbide paper in order to provide a very fine surface finish for subsequent surface and hardness analyses after exposure. After machining/grinding, the specimens were chemically degreased in trichloroethylene, ultrasonically cleaned in acetone, rinsed in ethyl alcohol, and air dried. After cleaning, the specimens were wrapped in pure Ta foil and annealed by (1) heating from room temperature to $525^{\circ} \mathrm{C}$ in a cryopumped vacuum of less than $1 \times 10^{-3} \mathrm{~Pa}$ at a rate of $500^{\circ} \mathrm{C} / \mathrm{h}$, and holding for $1 \mathrm{~h}$ to outgas any hydrogen that had been picked up by the specimens during processing; and (2) heating simultaneously from $525^{\circ} \mathrm{C}$ to $1000^{\circ} \mathrm{C}$, holding for $1 \mathrm{~h}$ at $1000^{\circ} \mathrm{C}$, and then cooling to approximately $400^{\circ} \mathrm{C}$ at a rate of $1000^{\circ} \mathrm{C} / \mathrm{h}$.

\subsection{EXPOSURE AND TEST CONDITIONS}

A long-term (nine-month) exposure of the annealed $\mathrm{V}-4 \mathrm{Cr}-4 \mathrm{Ti}$ alloy test specimens was then performed in the JFT-2M tokamak. The test specimens were positioned in the outward lower divertor chamber [16] of JFT-2M in a region away from direct interaction with the plasma. The specimen holding-fixture contained a heater to preheat the specimens to $300^{\circ} \mathrm{C}$ just prior to and during plasma discharges ("Sample bed" in Fig. 1). During their nine-month residence time in JFT-2M, the specimens experienced exposure to many environments: air; low-pressure hydrogen and deuterium $\left(\sim 10^{-5} \mathrm{~Pa}\right)$; redeposition of titanium (used for vessel interior conditioning via sputtering of titanium by Ar ions with magnetron-type rf discharges); and neutral high energy particles, including metallic species, during the approximately 200 lower single-null divertor shots for which high energy particle fluxes to the preheated test specimens were substantial. For 
these shots, the period of discharge flattop was $0.5 \mathrm{~s}$ and the duration of hydrogen neutral beam injection ( 0.3 $0.8 \mathrm{MW}$; for 114 out of 200 shots) was $0.2 \mathrm{~s}$. Typical operation parameters were: plasma current, $I_{p} \sim 200 \mathrm{kA}$; toroidal magnetic field, $B_{t} \sim 1.3 \mathrm{~T}$; lineaveraged main plasma electron density, $\bar{n}_{e}=2 \sim 6 \times 10^{19} \mathrm{~m}^{-3}$; electron density near divertor plate, $n_{e}^{a l v}=1 \sim 4 \times$ $10^{19} \mathrm{~m}^{-3}$; electron temperature near divertor plate, $T_{e}^{a l v}=6 \sim 20 \mathrm{eV}$; with plasma fuel gas of deuterium. Above the medium electron density, $-3 \times 10^{19} \mathrm{~m}^{-3}$, the divertor gas pressure increased to $10 \sim 50 \mathrm{mPa}$. After the discharge termination, the interior pressure reached $\sim 10^{-1} \mathrm{~Pa}$ and decayed with a time constant of the order of $1 \mathrm{~s}$.

The specimens were also exposed to approximately 2,010 upper single-null divertor shots and non-divertor shots (including disruptions developed prior to establishing the divertor configuration), for which high energy particle fluxes to the test specimens were relatively low. During most of these shots, the test specimens were near room temperature where particle retention was expected to be low.

After exposure, the bend specimens, standard CVN specimens, tensile specimens, and chemistry and hardness specimens were removed and evaluated in Japan; the miniature CVN specimens were evaluated by Argonne National Laboratory. At Hokkaido University, both unexposed (control) and exposed chemistry test specimens were measured for near-surface deuterium retention and chemical composition by thermal desorption spectroscopy (TDS) and Auger electron spectroscopy (AES). The surface topography of exposed specimens was also examined by scanning electron microscopy (SEM).

At JAERI, room-temperature uniaxial tensile tests and three-point bending (load versus deflection) tests were conducted on unexposed and exposed tensile specimens and standard bend specimens using an INSTRON screw-drive-type test machine. Charpy impact tests were performed on unexposed and exposed standard CVN specimens at room temperature. Microhardness measurements (Vickers) were performed on unexposed and exposed hardness specimens. At ANL, Charpy impact tests on miniature CVN specimens were conducted in air over a range of temperatures from liquid nitrogen temperature to $200^{\circ} \mathrm{C}$ with a Dynatup drop-weight tester following established procedures [13]. Specimen temperature during each test was measured with a thermocouple spot-welded to the end of the specimen. For the above-ambient-temperature tests, a hot-air blower was used to provide the heating. For the below-room-temperature tests, liquid nitrogen was used to chill the specimens. After testing, the fracture surfaces of the specimens were examined by SEM. 


\section{TEST RESULTS}

\subsection{DEUTERIUM RETENTION AND SURFACE ANALYSIS}

The TDS measurements indicated that the major gas species desorbed from an unexposed $\mathrm{V}$-alloy specimen (control) was $\mathrm{H}_{2}$, with a desorption peak observed at about $500^{\circ} \mathrm{C}$. Desorption of $\mathrm{H}_{2} \mathrm{O}, \mathrm{CO}$ and $\mathrm{CO}_{2}$ was also observed.

The major gas species observed to desorb from a JFT-2M-exposed V-alloy specimen was also $\mathrm{H}_{2}$, but the amount observed was approximately one-half of that desorbed from an unexposed specimen. Since the sample temperature during exposure to the plasma was about $300^{\circ} \mathrm{C}$, approximately half of the hydrogen present in the unexposed material was apparently desorbed at the exposure temperature. Deuterium was also observed to desorb from the exposed material. The retained amount of deuterium in the exposed material was $2 \times 10^{17} \mathrm{D} / \mathrm{cm}^{2}$, or $1.3 \mathrm{ppm}$, and was desorbed in the form of $\mathrm{HD}$ and $\mathrm{D}_{2}$. The peak temperatures for desorption of $\mathrm{HD}$ and $\mathrm{D}_{2}$ were approximately the same as that for $\mathrm{H}_{2}$, about $500^{\circ} \mathrm{C}$.

Chemical analysis (AES) measurements of the surface of an exposed sample revealed a deposited layer approximately $200 \mathrm{~nm}$ thick containing substantial $\mathrm{Ti}, \mathrm{Fe}, \mathrm{O}$, and $\mathrm{C}$, and traces of Cr. Measured concentrations of $\mathrm{Ti}, \mathrm{Fe}, \mathrm{O}$, and $\mathrm{C}$ at a depth of $\sim 100 \mathrm{~nm}$ were 28 at. \%, 18 at. \%, 18 at. $\%$, and 33 at. \%, respectively, although $\mathrm{C}$ levels were only slightly higher than values measured for an unexposed sample out to depths of $\sim 500 \mathrm{~nm}$. Below this deposited layer, measured $\mathrm{C}$ values remained nearly constant while Fe levels decreased to near zero at $\sim 280 \mathrm{~nm}$, and $\mathrm{Ti}$ and $\mathrm{O}$ levels decreased and reached values generally consistent with bulk chemistry values at $\sim 350 \mathrm{~nm}$. The deposition of titanium is not unexpected because of the titanium sputtering which is periodically utilized to condition the JFT-2M vessel interior. It is believed that the $\mathrm{Fe}, \mathrm{Cr}$, and $C$ resulted from the redeposition of species eroded by the plasma from the vessel wall, divertor, and/or baffle plate materials (all stainless steel components) and guard limiters (graphite), and $O$, and possibly some additional $\mathrm{C}$, was the result of interaction of the $\mathrm{V}$-alloy with various $\mathrm{O}$ - and $\mathrm{C}$-containing species present in the vessel environment (e.g., water vapor, $\mathrm{CO}, \mathrm{CO}_{2}$ ).

From the analysis performed, the deuterium retention was observed to be small, $1.3 \mathrm{ppm}$. The deposited layer may be in the form of an oxide and/or carbide, and may have played a role as a diffusion barrier for the deuterium flux from the divertor plasma. The color of the surface of exposed samples was yellow, which is consistent with the possible formation of titanium oxide in the deposition layer. In previous experiments at Hokkaido University on hydrogen absorption in a Ti-alloy, it was found that the hydrogen absorption was largely suppressed by a thin oxide layer at the surface [17]. This result may suggest that in order to minimize hydrogen uptake of $\mathrm{V}$-alloy components in a fusion device and to increase component lifetime, surface modifications such as the pre-operation formation of a thin oxide layer may be beneficial.

A SEM analysis of surfaces of the exposed chemistry specimens revealed a surface topography with features on the order of a few microns, and the topography was not substantially differ- 
ent than that observed for an unexposed specimen. The reason for the similar nature of the surfaces on unexposed versus exposed specimens is that the deposited layer on the exposed specimen was very thin $(200 \mathrm{~nm})$ and no erosion of the underlying metal appeared to have taken place.

\subsection{MECHANICAL PROPERTY TESTS}

The results of the room-temperature tensile tests (ultimate tensile strength and elongation) on unexposed and exposed V-alloy specimens are presented in Fig. 2. The data indicate that there is no substantial change in bulk tensile properties of the alloy as a result of the exposure in JFT-2M.

To evaluate delicate changes in mechanical properties after the tokamak exposure, bend tests were performed on unexposed and exposed bend test specimens. From the load versus deflection curves, the calculated elastic limit stress, $\sigma_{E}$, and deflection, $\varepsilon_{E}$, values corresponding to the deviation of the curve from linearity were developed. Figure 3 shows $\sigma_{E}$ and $\varepsilon_{E}$ values for V$4 \mathrm{Cr}-4 \mathrm{Ti}$ alloy before and after the tokamak exposure. Higher $\sigma_{E}$, with higher $\varepsilon_{E}$, values were observed after the tokamak exposure. These increases are consistent with a very slight strengthening of the exposed surfaces (stressed outer fibers) of the specimens due to impurity pickup, a strengthening that would not have been detected from the tensile test data.

Figures 4 and 5 show Charpy absorption energy versus lateral expansion and hardness level, respectively, as measured on the standard CVN and hardness test specimens before (control) and after the tokamak exposure. No remarkable or significant changes were observed after the tokamak exposure.

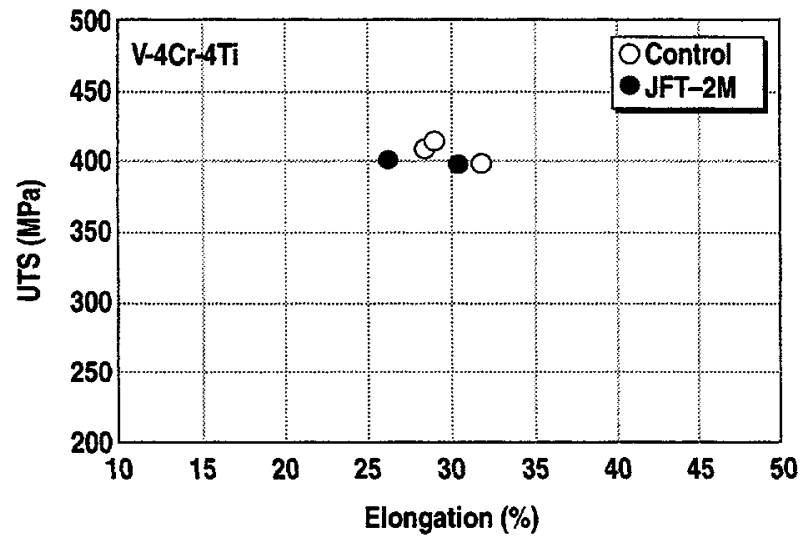

Fig. 2. Ultimate tensile strength (UTS) of $\mathrm{V}-4 \mathrm{Cr}-4 \mathrm{Ti}$ alloy before and after the long-term tokamak exposure test.

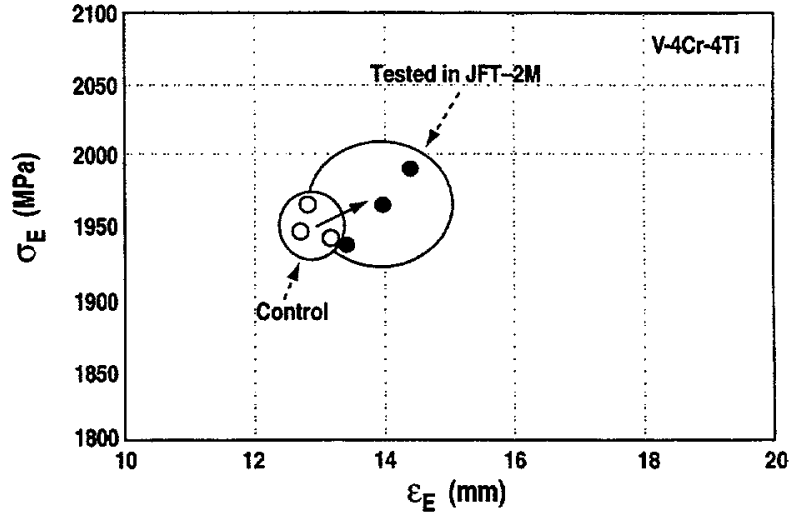

Fig. 3. The relationship between $\sigma_{E}$ and $\varepsilon_{E}$ of $V$ $4 \mathrm{Cr}-4 \mathrm{Ti}$ before and after the tokamak exposure. 


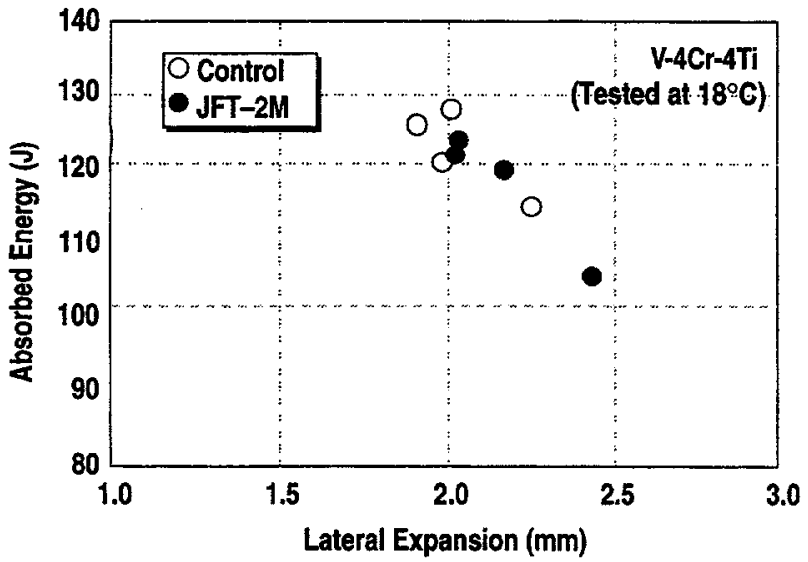

Fig. 4. The relationship between Charpy absorption energy and lateral expansion of $\mathrm{V}-4 \mathrm{Cr}$ $4 \mathrm{Ti}$ alloy before and after the tokamak exposure.

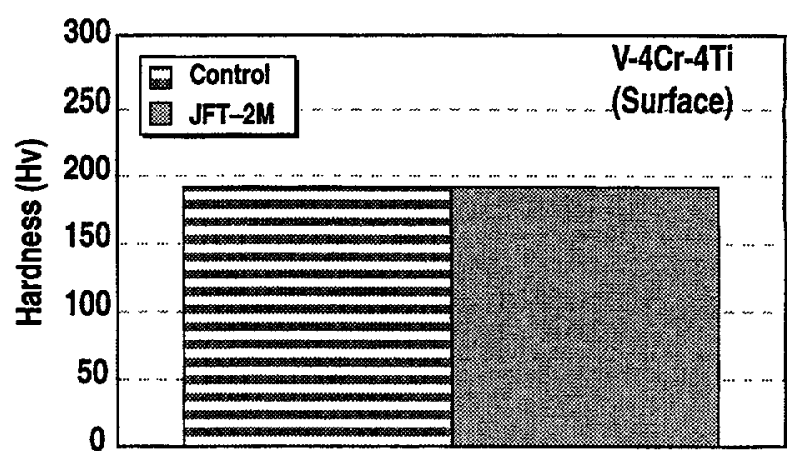

Fig. 5. Hardness of the V-4Cr-4Ti specimen surface before and after the tokamak exposure.

The results of the Charpy tests on JFT-2M-exposed miniature CVN specimens are summarized in Fig. 6 along with the results of tests performed on unexposed baseline (control) specimens. It appears that the impact properties of the JFT-2M-exposed specimens are essentially unchanged from the unexposed baseline properties. The exposed material still possesses excellent impact properties at temperatures as low as $-150^{\circ} \mathrm{C}$. A SEM fractographic examination of the tested specimens confirmed these positive findings. Even at a low temperature of $-150^{\circ} \mathrm{C}$, examination of the fracture surfaces of the specimen indicated that the fracture was by ductile tear. Only at $-195^{\circ} \mathrm{C}$ did the specimen fracture surface show evidence of brittle cleavage.

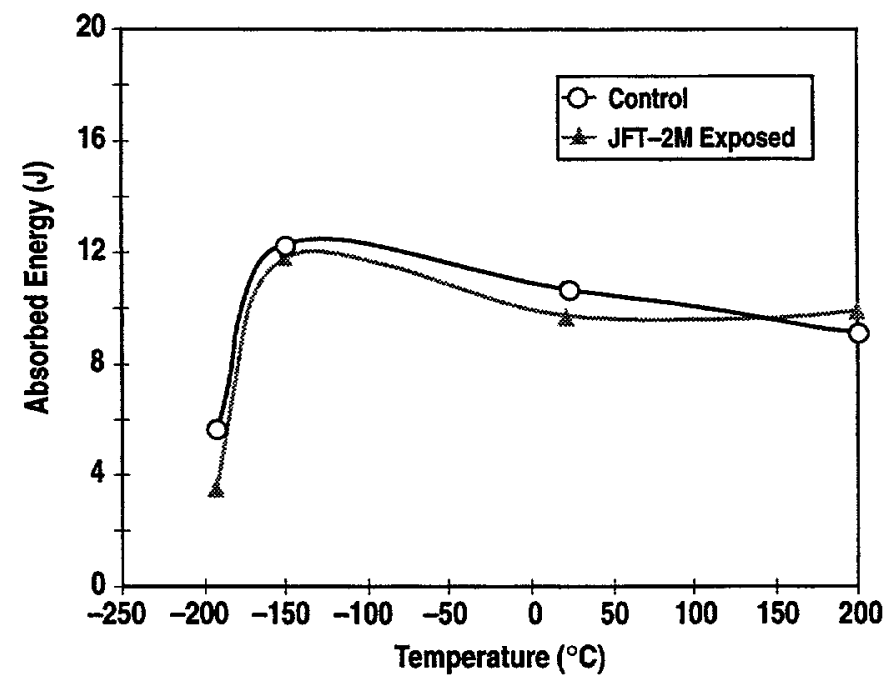

Fig. 6. Charpy impact properties of $\mathrm{V}-4 \mathrm{Cr}-4 \mathrm{Ti}$ alloy after JFT-2M exposure. 


\section{SUMMARY}

A collaborative $R \& D$ effort was conducted to investigate the influence of the nonplasmafacing environment, behind the divertor in the JFT-2M tokamak on the bulk properties and composition of alloy V-4Cr-4Ti. The mechanical property data developed for $\mathrm{V}-4 \mathrm{Cr}-4 \mathrm{Ti}$ alloy specimens after their exposure in the JFT-2M tokamak indicate that the JFT-2M environment did not significantly influence the bulk properties of the alloy. The changes observed in the material, e.g., by interstitial impurity uptake (or loss) and deposition, were limited to a shallow surface layer of the alloy, perhaps resulting in slight increases in strength in the layer as measured by bend tests. A decrease (desorption) in hydrogen content was observed in the $\mathrm{V}-4 \mathrm{Cr}-4 \mathrm{Ti}$ specimens after the tokamak exposure, and only a small amount of deuterium retention in the alloy was observed $(<2 \mathrm{ppm})$. The deposition layer observed may have played a role as a diffusion barrier for the deuterium flux from the divertor plasma. The findings are interpreted as being acceptable and supportive for the use of this vanadium alloy as a structural material in future fusion systems. 


\section{ACKNOWLEDGEMENTS}

This collaborative research and development work was conducted under a U.S.-Japan Fusion Cooperation Program (97FP3-10), and was supported by the U.S. Department of Energy, Office of Fusion Energy Sciences, under Contract Nos. DE-ACO3-99ER54463 (General Atomics) and W-31-109-Eng-38 (Argonne National Laboratory), and by internal research funds of General Atomics and the Japan Atomic Energy Research Institute. The authors also wish to thank the JFT-2M group for their assistance with the experiment. 


\section{REFERENCES}

[1] E.A. Hoffman, et al., Fusion Technology 31 (1997) 35.

[2] W.R. Johnson, et al., Advanced Materials and Processes 151 (1997) 25.

[3] D.L. Smith, et al., Fusion Engineering and Design 29 (1995) 399.

[4] D.L. Smith, et al., J. Nucl. Mater. 233-237 (1996) 356.

[5] J.P. Smith, et al., "Vanadium Alloys For The Radiative Divertor Program of DIII-D," Proc. 16th IEEE/NPS Symp. on Fusion Engineering, Champaign, Illinois, 1995, Vol. 1, p. 858 (Institute of Electrical and Electronics Engineers, Inc., Piscataway, New Jersey, 1996).

[6] J.P. Smith, et al., J. Nucl. Mater. 233-237 (1996) 421.

[7] W.R. Johnson, et al., Fusion Reactor Materials Semiannual Progress Report, DOE/ER-0313/19, Oak Ridge National Laboratory, Oak Ridge, Tennessee, 1996, p. 5.

[8] W.R. Johnson, et al., Fusion Reactor Materials Semiannual Progress Report, DOE/ER-0313/20, Oak Ridge National Laboratory, Oak Ridge, Tennessee, 1996, p. 3.

[9] W.R. Johnson, et al., Fusion Reactor Materials Semiannual Progress Report, DOE/ER-0313/21, Oak Ridge National Laboratory, Oak Ridge, Tennessee, 1997, p. 3.

[10] W.R. Johnson, et al., Fusion Reactor Materials Semiannual Progress Report, DOE/ER-0313/22, Oak Ridge National Laboratory, Oak Ridge, Tennessee, 1997, p. 8.

[11] W.R. Johnson, et al., J. Nucl. Mater. 258-263 (1998) 1425.

[12] J.P. Smith, et al., J. Nucl. Mater. 258-263 (1998) 1420.

[13] H.C. Tsai, et al., Fusion Reactor Materials Semiannual Progress Report, DOE/ER-0313/21, Oak Ridge National Laboratory, Oak Ridge, Tennessee, 1997, p. 10.

[14] H.C. Tsai, et al., Fusion Reactor Materials Semiannual Progress Report, DOE/ER-0313/23, Oak Ridge National Laboratory, Oak Ridge, Tennessee, 1998, p. 141.

[15] H.M. Chung, et al., Fusion Reactor Materials Semiannual Progress Report, DOE/ER-0313/18, Oak Ridge National Laboratory, Oak Ridge, Tennessee, 1995, p. 273.

[16] H. Kawashima, et al., Proc. 17th IAEA Conference on Fusion Energy, Yokohama, Japan, 1998 (Paper IAEA-F1-CN-69/EX3/4).

[17] Y. Hirohata, et al., J. Nucl. Mater. 266-269 (1999) 831. 